\title{
PENGEMBANGAN PERANGKAT PEMBELAJARAN MODEL GUIDED INQUIRY UNTUK MENURUNKAN MISKONSEPSI SISWA PADA MATERI OPTIK
}

\author{
Sufiyah $^{1)}$, Wasis ${ }^{2)}$, dan Soetjipto ${ }^{3)}$ \\ 1)Program Studi Pendidikan Sains, Program Pascasarjana Universitas Negeri Surabaya, \\ 2)Dosen Program Studi Pendidikan Sains, Program Pascasarjana Universitas Negeri Surabaya \\ 3)Dosen Program Studi Pendidikan Sains, Program Pascasarjana Universitas Negeri Surabaya \\ Email: sufiyahansori@gmail.com
}

\begin{abstract}
Abstrak: Penelitian ini bertujuan mendeskripsikan kelayakan perangkat pembelajaran model guided inquiry untuk menurunkan miskonsepsi siswa MAN Bangkalan pada materi optik menggunakan model pengembangan Borg and Gall. Perangkat pembelajaran berupa Silabus, RPP, Buku Ajar Siswa, LKS, dan Lembar Penilaian Hasil pengembangan perangkat divalidasi oleh 5 orang validator. Uji coba perangkat menggunakan one grup pretes posttest design pada kelas XI MIPA 3 dan kelas XI MIPA 4 MAN Bangkalan. Teknik analisis data yang digunakan adalah deskriptif teknik inferensial Kruskal Wallis dan Wilcoxon's Sign Rank Test. Hasil penelitian berupa: (1) Validitas perangkat yang dikembangkan dinyatakan sangat valid berdasarkan skor yang diperoleh dari validator, (2) Kepraktisan perangkat yang dikembangkan ditinjau dari aspek keterlaksanaan perangkat dan aspek aktivitas siswa yang berkategori baik berdasarkan skor yang diperoleh dari pengamat, dan (3) Efektivitas perangkat yang dikembangkan ditinjau dari dampak penurunan beban miskonsepsi siswa kelas XI MIPA 3 awalnya 57\% menjadi 3\% dan siswa kelas XI MIPA 4 awalnya 53\% menjadi $3 \%$.
\end{abstract}

Kata Kunci: pengembangan, perangkat, pembelajaran, model guided inquiry, miskonsepsi, optik.

\section{PENDAHULUAN}

Beberapa penelitian miskonsepsi pada konsep optik sudah dilakukan. Penelitian Suwarna (2012), menunjukkan persentase miskonsepsi materi optik sebesar $31,7 \%$, persentase miskonsepsi materi listrik dinamis $16,2 \%$, dan persentase miskonsepsi suhu dan kalor sebesar 18,3\%. Miskonsepsi materi optik memiliki persentase paling tinggi dibandingkan kedua materi tersebut. Suwarna mengatakan bahwa pada materi optik persentase miskonsepsi pemantulan cahaya sekitar $41,1 \%$, persentase miskonsepsi pembiasan cahaya sekitar 26,1\%, dan persentase miskonsepsi alat optik sekitar 19,7\%. Jenis konsep yang mengalami miskonsepsi adalah konsep abstrak dan contoh konkret sebanyak $20,8 \%$, menyatakan simbol sebanyak 10,6\% dan contoh konsep konkret sebanyak $40 \%$.

Penelitian Handayani, dkk (2013) mengenai miskonsepsi pada beberapa siswa SMP di Kalimantan mendapatkan bahwa pada SMP 6 Pontianak sekitar lebih 50\% siswa, sekitar 79,21\% siswa SMP Kristen I Pontianak, sekitar 69,67\% siswa SMP 1 Pontianak mengalami miskonsepsi pada pemantulan cahaya. Miskonsepsi ini diremidiasi dan mengalami penurunan sebesar $27 \%$ masih menyisakan sekitar $42,67 \%$ siswa yang masih mengalami miskonsepsi, selanjutnya untuk mengetahui fakta di lapangan peneliti melakukan prapenelitian untuk mengetahui miskonsepsi pada materi optik. Subjek prapenelitian adalah siswa kelas XI MIPA di MAN Bangkalan yang sudah mendapatkan materi pelajaran optik di kelasnya. Hasil prapenelitian menunjukkan bahwa dari 129 siswa yang diberikan soal optik hampir $74,5 \%$ siswa masih belum bersih dari miskonsepsi hanya 4,82\% saja yang tahu konsep dan 20,67\% siswa yang tidak tahu konsep. Hasil prapenelitian menunjukkan bahwa $73,25 \%$ siswa miskonsepsi pada hukum pemantulan Snell, 66\% siswa mengalami miskonsepsi pada pembentukan bayangan pada cermin cekung, 74\% siswa miskonsepsi pada pembiasan, $81 \%$ siswa miskonsepsi pada pembentukan bayangan pada lensa cembung. Hasil tes ini menunjukkan bahwa siswa MAN Bangkalan masih mengalami miskonsepsi pada konsep optik yang cukup serius.

Miskonsepsi ini perlu direduksi agar tidak terjadi berulang-ulang dan melekat pada benak siswa sehingga diperlukan pembelajaran yang dapat menurunkan miskonsepsi ini. Sejumlah model pembelajaran dikembangkan untuk membantu guru dalam menurunkan miskonsepsi. Pendapat Bruner learning by doing menjadi salah satu alternatif dalam menurunkan miskonsepsi ini. Guru dalam mengajar diharapkan dapat mengatur atau menyiapkan pembelajaran yang berorientasi pada pengalaman belajar siswa sendiri dengan melibatkan proses berpikir. Siswa membutuhkan pengembangan 
keterampilan berpikir saintifik untuk menggunakan konsep-konsep yang siswa miliki dalam menyelesaikan masalah. Siswa dilibatkan dalam proses berpikir yang menyebabkan siswa aktif dalam konflik kognitif agar proses perubahan konseptual dalam diri siswa terjadi.

Miskonsepsi dapat diturunkan jika siswa bekerja seperti ilmuwan, karena level berpikir siswa tidak seperti ilmuwan maka siswa perlu mendapatkan pembimbingan. Salah satu pembelajaran yang didalamnya terdapat proses pembimbingan adalah pembelajaran model guided inquiry sebagai bentuk usaha untuk mereduksi miskonsepsi yang dialami siswa. Pembelajaran model guided inquiry merupakan salah satu jenis model pembelajaran inquiry melalui bimbingan guru terhadap siswa dalam melakukan kegiatan dengan memberikan permasalahan, mengarahkannya pada pertanyaan-pertanyaan ilmiah, mengarahkannya pada hipotesis, kemudian membuktikan melalui percobaan yang dirancang sendiri melalui bimbingan guru, dan kemudian mengevaluasi kegiatan dan pengetahuan siswa sendiri, dengan demikian siswa akan aktif dalam mengkonstruk pengetahuan siswa, pada akhirnya akan merubah konsepsi awal yang tidak sesuai tersebut. Pembelajaran model guided inquiry berpotensi dapat menurunkan miskonsepsi karena dalam setiap langkah guided inquiry terdapat target yang berisi informasi-informasi yang diperoleh siswa melalui pengalaman belajarnya dan kemudian informasi yang baru diperoleh melalui kegiatan pembelajaran ini, kemudian siswa mengasimilasi pengetahuan itu kedalam stuktur kognitif siswa pada akhirnya siswa akan mengganti prakonsepsi dengan konsep baru yang ilmiah. Model pembelajaran guided inquiry ini dipilih sebagai cara untuk menurunkan miskonsepsi siswa dengan alasan siswa yang mengalami miskonsepsi pengetahuannya harus ditantang, agar konsepsi siswa yang salah ini tidak terintegrasi ke dalam struktur kognitif siswa dan mengganggu pembelajaran berikutnya (Wenning, 2008).

Perangkat pembelajaran merupakan salah satu faktor yang mempunyai peranan penting dalam proses pembelajaran, karena tanpa adanya perangkat pembelajaran maka proses pembelajaran yang dilakukan tidak akan berlangsung dengan baik. Perangkat pembelajaran mempengaruhi keberhasilan proses pembelajaran di kelas. Syarat perangkat pembelajaran yang berkualitas adalah valid, praktis, dan efektif (Nieveen, 2007). Kualitas perangkat pembelajaran ditinjau dari aspek validitas apabila perangkat pembelajaran dinilai baik oleh para ahli atau validator. Kualitas perangkat pembelajaran ditinjau dari aspek kepraktisan apabila ketika digunakan dan realitanya menunjukkan bahwa mudah bagi guru dan peserta didik untuk menggunakan perangkat pembelajaran tersebut. Hal ini berarti terdapat konsistensi antara harapan dengan pertimbangan dan harapan dengan operasional. Apabila kedua konsistensi tersebut tercapai, maka produk hasil pengembangan dapat dikatakan praktis. Kualitas perangkat pembelajaran ditinjau dari aspek keefektivan apabila ketika digunakan menunjukkan hasil yang sesuai yang diharapkan.

Berdasarkan latar belakang dan data prapenelitian tersebut peneliti melakukan penelitian dengan membuat perangkat pembelajaran yang dapat menurunkan miskonsepsi ini. Penelitian ini dilaksanakan dengan cara pertama peneliti membuat perangkat pembelajaran, memvalidasi perangkat. Kedua perangkat diujicobakan pada siswa untuk mengetahui bahwa perangkat pembelajaran model guided inquiry memberikan dampak pada penurunan beban miskonsepsi yang dialami siswa.

Berdasarkan latar belakang di atas, maka yang menjadi rumusan masalah dalam penelitian ini adalah "Bagaimanakah kelayakan perangkat pembelajaran model guided inquiry untuk menurunkan miskonsepsi siswa MAN Bangkalan pada materi optik?

\section{METODE PENELITIAN}

Penelitian ini merupakan penelitian pengembangan sebuah produk berupa perangkat pembelajaran model guided inquiry dengan menggunakan model pengembangan Borg and Gall (Borg and Gall, 2007).

Perangkat pembelajaran yang dihasilkan berupa silabus, RPP, Buku Ajar Siswa, LKS, dan penilaian menggunakan model guided inquiry yang akan digunakan untuk menurunkan miskonsepsi. Perangkat pembelajaran digunakan untuk mendapatkan data berupa validitas perangkat, kemudian keterlaksanaan diujicobakan dengan menggunakan rancangan one group pretest-posttest design.. Obyek uji coba perangkat pembelajaran adalah siswa XI MIPA 3 dan XI MIPA 4 tahun pelajaran 2016-2017 di MAN Bangkalan dan dilaksanakan pada bulan Juni s.d. Desember 2016 semester gasal tahun pelajaran 2016/2017.

Data validitas dianalisis dengan diinterpretasikan sesuai dengan Tabel 3.2.

Tabel 1 Interval Validasi Perangkat

\begin{tabular}{|c|c|c|}
\hline No & Interval & Tingkat Validitas \\
\hline 1 & $1,0-1,5$ & Tidak Baik/Tidak Valid \\
\hline 2 & $1,6-2,5$ & Kurang Baik/Kurang Valid \\
\hline 3 & $2,6-3,5$ & Cukup Baik/Valid \\
\hline 4 & $3,6-4,0$ & Baik/Sangat Valid \\
\hline
\end{tabular}
Riduwan, 2012 
Statistik non-parametik uji uji Kruskal Wallis digunakan untuk mengetahui kesamaan antara validator terhadap penilaian yang diberikan pada tiap aspek validasi (Djarwanto, 1991). Kriteria penilaian item butir soal pada lembar penilaian pengetahuan dan keterampilan, hasil penilaian validasi isi dan bahasa penulisan soal penilaian item butir soal disimpulkan dengan menggunakan:

$$
\begin{aligned}
& \mathrm{SV}=\text { Sangat Valid (5) } \\
& \mathrm{V}=\text { Valid (4) } \\
& \mathrm{CV}=\text { Cukup Valid (3) } \\
& \mathrm{KV}=\text { Kurang Valid (2) } \\
& \mathrm{TV}=\text { Tidak Valid (1) }
\end{aligned}
$$

$$
\text { Ratumanan, } 2011
$$

Analisis keterlaksanaan pembelajaran yang diterapkan dalam penelitian ini berdasarkan pada hasil pengamatan pengamat terhadap aktivitas guru dalam siswa selama pembelajaran berlangsung menggunakan lembar keterlaksanaan pembelajaran (LKP). Persentase keterlaksanaan strategi pembelajaran dengan menggunakan persamaan:

$\mathrm{P}=\frac{\sum \text { Skor yang diperoleh }}{\sum \text { Total skor }} \times 100 \%$

Arifin, 2010

Menginterpretasikan persentase keterlaksanaan model pembelajaran guided inquiry yang diperoleh menggunakan Tabel 2.

Tabel 2 Kriteria Keterlaksanaan RPP

\begin{tabular}{|c|c|c|}
\hline No. & Persentase & Kategori \\
\hline 1. & $0 \%-20 \%$ & Sangat kurang \\
\hline 2. & $21 \%-40 \%$ & Kurang \\
\hline 3. & $41 \%-60 \%$ & Cukup \\
\hline 4. & $61 \%-80 \%$ & Baik \\
\hline 5. & $81 \%-100 \%$ & Sangat baik \\
\hline
\end{tabular}

Riduwan, 2012

Data penilaian dari pengamat kemudian diuji untuk mengetahui kesamaan persepsi antara pengamatr terhadap penilaian keterlaksanaan pembelajaran yang telah dilakukan dengan menggunakan uji Kruskal Wallis menggunakan SPSS 16.0.

Uji efektivitas menggunakan statistik non-parametrik uji Wilcoxon's Signed Rank Test digunakan untuk menguji perubahan MK3 yang dialami setiap siswa sebelum dan sesudah pembelajaran menggunakan guided inquiry.

Hambatan selama pelaksanaan pembelajaran dianalisis dengan deskriptif kualitatif, yaitu guru, pengamat, dan peneliti memberikan catatan tentang hambatan atau kendala yang terjadi selama pelaksanaan pembelajaran.

Pengembangan Perangkat Pembelajaran Model Guided

Inquiry...............

\section{PEMBAHASAN}

Hasil penelitian yang akan dibahas meliputi kelayakan perangkat berupa validitas, kepraktisan, dan efektivitas.

\section{A. Validasi Perangkat Pembelajaran Guided Inquiry untuk Menurunkan Miskonsepsi Optik Siswa MAN Bangkalan}

Pemilihan materi yang akan dikembangkan ditentukan dari hasil telaah terhadap penelitian sebelumnya yang ada dan hasil prapenelitian di sekolah yang akan dijadikan tempat penelitian. Hasil telaah dan prapenelitian menjadi dasar untuk mencari jalan keluar dari persoalan miskonsepsi materi yang telah dikaji. Penyebab miskonsepsi menjadi dasar untuk menentukan model pembelajaran yang cocok untuk pengembangan perangkat ini. Model guided inquiry menjadi solusi untuk menurunkan miskonsepsi karena model ini sesuai dengan teori Piaget tentang pengetahuan bahwa siswa selalu beradaptasi dengan lingkungan sekitarnya. Proses adaptasi merupakan hasil pengalamannya berinteraksi dengan lingkungannya.

Tabel 3 Hasil validasi silabus dan RPP

\begin{tabular}{|c|l|c|}
\hline No. & \multicolumn{1}{|c|}{ Aspek yang dinilai } & Rerata \\
\hline 1 & Indikoator Silabus & 3,90 \\
\hline 2 & Skenario Silabus & 3,90 \\
\hline 3 & $\begin{array}{l}\text { Rumusan Indikator Fase } \\
\text { Pembelajaran Guided Inquiry }\end{array}$ & 3,80 \\
\hline 4 & $\begin{array}{l}\text { Rumusan Indikator } \\
\text { Keterampilan Proses Sains }\end{array}$ & 3,80 \\
\hline 5 & $\begin{array}{l}\text { Mengunakan domain Afektif, } \\
\text { Kognitif, dan Psikomotor }\end{array}$ & 3,85 \\
\hline 6 & Indikoator RPP In Indikator & 3,83 \\
\hline 7 & Skenario RPP & 3,90 \\
\hline 8 & $\begin{array}{l}\text { Rumusan Indor } \\
\text { Pembelajaran Guided Inquiry }\end{array}$ \\
\hline 9 & $\begin{array}{l}\text { Rumusan } \\
\text { Keterampilan Proses Sains }\end{array}$ \\
\hline 10 & $\begin{array}{l}\text { Mengunakan domain Afektif, } \\
\text { Kognitif, dan Psikomotor }\end{array}$ & 3,85 \\
\hline 11 & Menurunkan Miskonsepsi & 3,80 \\
\hline 12 & Kegayutan Silabus dan RPP & 3,80 \\
\hline & \multicolumn{2}{|c|}{} \\
\hline
\end{tabular}

Tabel 3 Hasil validasi BAS

\begin{tabular}{|c|l|c|}
\hline No. & \multicolumn{1}{|c|}{ Aspek yang Dinilai } & Rerata \\
\hline 1 & Buku Bagian Awal & 4,00 \\
\hline 2 & Pendahuluan. & 3,80 \\
\hline 3 & Launch Lab & 3,60 \\
\hline
\end{tabular}




\begin{tabular}{|c|c|c|}
\hline 4 & Isi Materi (halaman 3-40) & 3,60 \\
\hline 5 & Relevansi & 3,70 \\
\hline 6 & $\begin{array}{lrr}\text { Kesesuaian } & \text { Sajian } & \text { Materi } \\
\text { Dengan } & \text { Model } \\
\text { Pembelajaran } & \text { guided } \\
\text { inquiry dan } & \text { Menurunkan } \\
\text { Miskonsepsi } & \text { (halaman 3- } \\
\text { 40) } & \end{array}$ & 3,72 \\
\hline 7 & $\begin{array}{l}\text { Kesesuaian Bahasa Yang } \\
\text { Digunakan (halaman 3-40) }\end{array}$ & 3,60 \\
\hline 8 & $\begin{array}{l}\text { Keterbacaan dan } \\
\text { Kekomunikatifan Isi Materi } \\
\text { (halaman 3-40) }\end{array}$ & 3,73 \\
\hline
\end{tabular}

Tabel 4 Hasil validasi LKS

\begin{tabular}{|c|c|c|}
\hline No. & Aspek yang Dinilai & Rerata \\
\hline 1. & $\begin{array}{l}\text { Terdapat petunjuk penggunaan } \\
\text { LKS. }\end{array}$ & 3,00 \\
\hline 2. & $\begin{array}{l}\text { Memfasilitasi pencapaian tujuan } \\
\text { pembelajaran. }\end{array}$ & 3,80 \\
\hline 3. & $\begin{array}{l}\text { Memfasilitasi pengalaman belajar } \\
\text { dalam model pembelajaran guided } \\
\text { inquiry. }\end{array}$ & 3,60 \\
\hline 4. & $\begin{array}{l}\text { Penyajian materi/konsep sistematis, } \\
\text { logis dan lugas. }\end{array}$ & 3,65 \\
\hline 5. & Kesesuaian gambar dengan konsep. & 3,30 \\
\hline 6. & $\begin{array}{l}\text { Cakupan materi/konsep } \\
\text { RPP. }\end{array}$ & 3,45 \\
\hline 7. & $\begin{array}{l}\text { Tugas-tugas yang diberikan dalam } \\
\text { LKS membantu siswa untuk } \\
\text { mencapai tujuan pembelajaran. }\end{array}$ & 3,55 \\
\hline 8. & $\begin{array}{l}\text { Kesesuaian konsep dalam LKS } \\
\text { dengan konsep yang dikemukakan } \\
\text { oleh para ahli. }\end{array}$ & 3,55 \\
\hline 9. & $\begin{array}{l}\text { Kebenaran dan ketepatan istilah } \\
\text { yang digunakan. }\end{array}$ & 3,65 \\
\hline 10. & $\begin{array}{l}\text { Melatihkan semua indikator } \\
\text { keterampilan proses sains dasar } \\
\text { dan keterampilan proses sains } \\
\text { terpadu. }\end{array}$ & 3,40 \\
\hline
\end{tabular}

Hasil analisis validitas perangkat ditentukan dengan cara mencocokkan hasil rata-rata penilaian validator dengan kriteria yang telah ditentukan. Berdasarkan ratarata penilaian yang diberikan validator adalah 3-4 yang artinya perangkat layak digunakan tanpa revisi. Keajegan penilaian validator di uji dengan uji Kruskal Wallis didapatkan validator menilai perangkat ini tidak ada perbedaan penilaian dan memenuhi syarat valid untuk digunakan dalam pembelajaran.

\section{B. Kepraktisan Perangkat Pembelajaran}

Pengamatan terhadap keterlaksanaan pembelajaran bertujuan untuk mengetahui keberhasilan dalam menerapkan tahapan-tahapan guided inquiry sesuai yang direncanakan. Sintak guided inquiry yang dikembangkan adalah sintaks Joyce and Weill (2012) dengan menyisipkan kegiatan pemrosesan informasi sebagai upaya untuk merubah skema konsepsi siswa yang salah menggunakan proses asimilasi dan adapatasi terhadap pengetahuan baru yang diperoleh saat melaksanakan pembelajaran guided inquiry. Komponen sintak pembelajaran yang dinilai dari lima kegiatan utama, yaitu pendahuluan, kegiatan inti, penutup, pengelolaan waktu dan antusiasme. Kegiatan inti ini dari model pembelajaran guided inquiry meliputi: menjelaskan proses inquiry, menyajikan masalah, merumuskam hipotesis, melakukan penyelidikan dan organisasi data, analisis data dan menarik simpulan, dan merefleksikan proses inkuiri. Hal ini sesusai dengan sintak model pembelajaran inquiry yang disarankan oleh Joyce and Weill (2012).

Tabel 5 Keterlaksanaan Pembelajaran

\begin{tabular}{|c|l|c|}
\hline No & \multicolumn{1}{|c|}{$\begin{array}{c}\text { Komponen Sintaks } \\
\text { Pembelajaran }\end{array}$} & Rerata \\
\hline I & Pendahuluan & 4,00 \\
\hline II & Kegiatan Inti & 3,50 \\
\hline III & Penutup & 4,00 \\
\hline IV & $\begin{array}{c}\text { Pengelolaan waktu dan } \\
\text { antusiasme siswa }\end{array}$ \\
\hline
\end{tabular}

Penilaian keterlaksanaan dilakukan 0leh empat pengamat pada empat tatap muka di kelas XI MIPA 3 dan XI MIPA 4 bernilai baik. Hasil uji Kruskal Wallis yang membandingkan skor-skor penilaian sintaks pada keempat pengamat diperoleh signifikansi lebih besar dari 0.05. artinya, dengan taraf kepercayaan $95 \%$ disimpulkan tidak ada perbedaan skor signifikan atas penilaian keterlaksanaan sintaks antara keempat pengamat. Artinya bahwa guru telah secara ajeg dan konsisten menjalankan sintaks pembelajaran pada setiap tatap muka.

Pelaksanaan pembelajaran model guided inquiry yang dikembangkan terdapat beberapa kendala-kendala yang dihadapi guru selama proses belajar mengajar berlangsung. Kendala pembelajaran adalah ada beberapa kelompok siswa yang kesulitan dalam menyusun hipotesis, menganalisis data dan menarik kesimpulan. 


\section{Keefektifan Perangkat Pembelajaran}

Hasil uji coba perangkat untuk mendapatkan data efektivitas didapatkan bahwa awal MK 3 sangat tinggi pada tes awal (pretest) diperoleh data empiris dari empat konsep yang diujikan siswa masihi mengalami miskonsepsi.

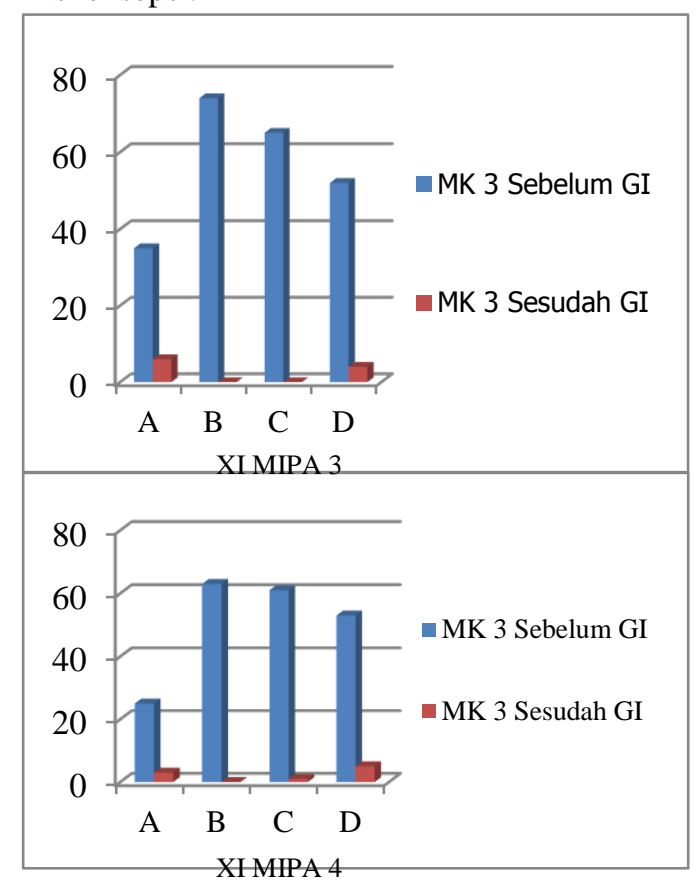

Fenomena terjadinya kesalahan pada prakonsepsi siswa sesuai dengan pernyataan Suparno (2013) yang menyatakan bahwa prakonsepsi siswa mengalami kesalahan karena prakonsepsi dibentuk sebelum siswa mendapatkan pelajaran formal tentang konsep yang di maksud. Menurut Ibrahim (2012) miskonsepsi (MK1, MK2, dan MK3) yang terjadi pada siswa kelas XI MIPA 3 dan siswa kelas XI MIPA 4 ini adalah sebuah kewajaran, karena pada dasarnya prakonsepsi saat ini adalah konsepsi yang didapatkan dari pemahaman terhadap fenomena alam (lingkungan) atau hasil pengalaman siswa sebelumnya. Konsepsi setelah pembelajaran berubah menjadi tahu konsep setalah pembelajaran modek guided inquiry diterapkan. Pengalaman selama penyelidikan melalui bimbingan guru ini menjadikan intuisi siswa tertantang (Suparno, 2013). Siswa kemudian mengadaptai atau mengasimilasi pengetahuan yang didapatkan dari penyelidikan terssebut ke dalam skema pikirannya. Perubahan konsepsi siswa berfungsi untuk menafsirkan pengetahuan baru yang sedang dihadapinya, dan berkembang terus karena dapat mengalami revisi berdasarkan pengalaman yang telah dialaminya.

Konsepsi siswa yang sulit berubah meskipun dikenalkan dengan konsep yang benar disebut resisten.
Resisteninya sebuah miskonsepsi karena dapat mengalami revisi berdasarkan pengalaman yang telah dialaminya ( Bodner 1986).

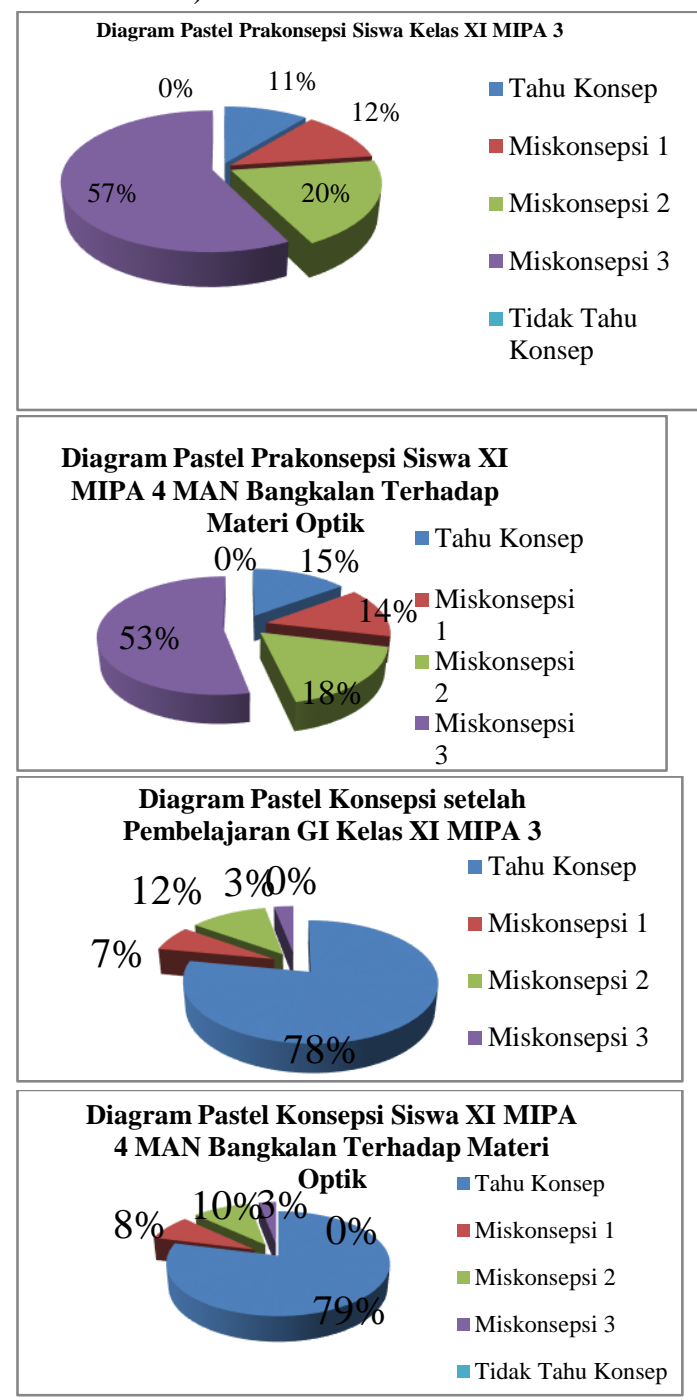

Terlihat dari Analisis deskriptif persentase beban miskonsepi berubah dari sebelum pembelajaran guided inquiry $57 \%$ berubah menjadi $3 \%$ di kelas XI MIPA 3 dan $53 \%$ menjadi $3 \%$. Analisis deskriptif beban miskonsepsi dibuktikan dengan uji Wilcoxon's Signed Rank Test tersebut didapat adalah untuk kelas XI MIPA 3 adalah Z hitung $(-3,210)>Z$ tabel $(1,96)$ sedangkan untuk kelas XI MIPA 4 adalah $Z$ hitung $(-3,553)>Z$ tabel $(1,96)$ yang artinya profil konsepsi siswa kedua kelas tersebut sebelum dan sesudah pembelajaran guided inquiry berbeda secara signifikan, maka dapat dibuktikan bahwa pembelajaran guided inquiry secara klasikal pada optik dapat menurunkan miskonsepsi. Hal ini menjadi petunjuk bahwa pembelajaran model guided inquiry dapat menurukan beban miskonsepsi yang ditanggung siswa kelas XI MIPA 3 dan XI MIPA 4 MAN Bangkalan 


\section{SIMPULAN}

Berdasarkan data hasil penelitian, analisis dan diskusi hasil penelitian, maka dapat dibuat kesimpulan bahwa perangkat pembelajaran model guided inquiry yang dikembangkan telah memenuhi syarat valid, praktis, dan efektif menurunkan miskonsepsi siswa MAN Bangkalan pada materi optik, sehingga layak digunakan dalam proses belajar mengajar.

\section{DAFTAR PUSTAKA}

Arifin, Z. 2010. Evaluasi Pembelajaran. Bandung: PT Remaja Rosdakarya

Bodner, G. M. 1986. Constructivism: A Theory of Knowledge. Journal of Chemical Education, Vol.63 No.10, pp. 1-15.

Borg, W. R., Gall, J. P., and Gall, M.D. 2007. Educational Research: An Introduction Eight Edition. New York: Longman.

Handayani, A. D., Sahala, S. S., dan Arsyid, S. B. 2013. Remediasi Miskonsepsi Siswa Menggunakan Eksperimen Berbantuan Tutor Sebaya Pada Materi Cermin SMP. Article Published Online diakses pada tanggal 14 September 2015.
Ibrahim, M. 2012. Konsep Miskonsepsi dan Cara Mengatasinya. Surabaya: Unesa Unuversity Press.

Nieven, Nieveen. Plomp, Tjeerd (2007). An Introduction to Educational Design Research. Netherland: Netherlands institute for curriculum development.

Ratumanan, G. T. 2011. Evaluasi Hasil Belajar pada Tingkat Satuan Pendidikan. Surabaya: Unesa University Press

Riduwan. 2012. Skala Pengukuran Variabel- Variabel Penelitian. Bandung: Alfabeta.

Sugiyono. 2012. Metode Penelitian Kuantitatif Kualitatif dan $R \& D$. Bandung: Alfabeta.

Sugiyono. 2007. Statistika untuk Penelitian. Bandung: Alfabeta.

Suparno, P. 2013. Miskonsepsi dan Perubahan Konsep Pendidikan Fisika. Jakarta: Grasindo.

Suwarna. 2012. Analisis Miskonsepsi Siswa SMA Kelas X Pada Mata Pelajaran Fisika Melalui CRI (Certainty of Response Index) Termodifikasi. Jurnal Laporan Lemlit. UIN Syarif Hidayatullah Jakarta.

Wenning, J. 2008. Level of Inquiry: Hirarchies of Pedagogical Practices and Inquiry Processes. Journal of Physics Teacher Education.Vol. 2 No. 3, pp. 3-11. 